\title{
Ecological Memory of Historical Contamination Influences the Response of Phytoplankton Communities
}

\author{
Didier L. Baho, ${ }^{1,2 *}$ Simone Rizzuto, ${ }^{3}$ Luca Nizzetto, ${ }^{1,4 *}$ Dag O. Hessen, ${ }^{5}$ \\ Jon Norberg, ${ }^{6}$ Birger Skjelbred, ${ }^{1}$ Kevin C. Jones, ${ }^{3}$ Hao Zhang, ${ }^{3}$ and Eva Leu ${ }^{7}$
}

\begin{abstract}
${ }^{1}$ Norwegian Institute for Water Research (NIVA), Gaustadalléen 21, 0349 Oslo, Norway; ${ }^{2}$ Department of Aquatic Sciences and Assessment, Swedish University of Agricultural Sciences, Uppsala, Sweden; ${ }^{3}$ Lancaster Environment Centre, Lancaster University, Lancaster, UK; ${ }^{4}$ RECETOX, Masarik University, Kamenice 753/5, 62500 Brno, Czech Republic; ${ }^{5}$ Department of Biosciences, University of Oslo, Blindern, Box 1066, 0316 Oslo, Norway; ${ }^{6}$ Stockholm Resilience Centre, Stockholm University, Kräftriket 2B, 10691 Stockholm, Sweden; ${ }^{7}$ Akvaplan-Niva, CIENS, Science Park, Gaustadalléen 21, 0349 Oslo, Norway
\end{abstract}

\begin{abstract}
Ecological memory (EM) recognizes the importance of previous stress encounters in promoting community tolerance and thereby enhances ecosystem stability, provided that gained tolerances are preserved during non-stress periods. Drawing from this concept, we hypothesized that the recruitment of tolerant species can be facilitated by imposing an initial sorting process (conditioning) during the early stages of community assembly, which should result in higher production (biomass development and photosynthetic efficiency) and stable community composition. To test this, phytoplankton resting stages were germinated from lake sediments originating from two catchments that differed in contamination history: one im-
\end{abstract}

Received 8 July 2020; accepted 10 January 2021; published online 22 March 2021

Supplementary Information: The online version contains supplementary material available at https://doi.org/10.1007/s10021-021-0060 4-0.

Author contributions DLB, LN, DOH, JN and EL conceived the study and designed the experiment. DLB, SR, LN and EL carried out the experiment. The taxonomic classification and enumeration of phytoplankton was performed by BS. DLB and SR analyzed the data and took the lead in writing the manuscript. All authors provided critical analysis of results, feedbacks, helped structuring and editing the manuscript.

*Corresponding author; e-mail: didier.baho@slu.se; luca.nizzetto@niva.no pacted by long-term herbicides and pesticides exposures (historically contaminated lake) from an agricultural catchment compared to a low-impacted one (near-pristine lake) from a forested catchment. Conditioning was achieved by adding an herbicide (Isoproturon, which was commonly used in the catchment of the historically contaminated lake) during germination. Afterward, the communities obtained from germination were exposed to an increasing gradient of Isoproturon. As hypothesized, upon conditioning, the phytoplankton assemblages from the historically contaminated lake were able to rapidly restore photosynthetic efficiency $(p>0.01)$ and became structurally (community composition) more resistant to Isoproturon. The communities of the near-pristine lake did not yield these positive effects regardless of conditioning, supporting that EM was a unique attribute of the historically stressed ecosystem. Moreover, assemblages that displayed higher structural resistance concurrently yielded lower biomass, indicating that benefits of EM in increasing structural stability may trade-off with production. Our results clearly indicate that EM can foster ecosystem stability to a recurring stressor. 
Key words: Ecological memory; Phytoplankton communities; Stability; Recurrent stressor; Community tolerance; Trade-off.

\section{HighLights}

- Contamination history determines community responses when a stressor recur.

- Communities that had previous encounters with stressor(s) show higher resistance.

- Higher community resistance can result in a trade-off with biomass production.

\section{INTRODUCTION}

The concept of ecological memory (EM; Padisak 1992) proposes that past experience influences present day responses of ecosystems, thereby enabling communities to cope better with recurrent stress (Turner 2010; Johnstone and others 2016). Ecosystems that have been exposed to recurrent stressor(s) can acclimatize and eventually adapt (Ogle and others 2015; Samani and Bell 2016) through physiological, ecological and evolutionary processes (Collins and Gardner 2009). Over longer time scales, adaptations involving ecological (Blanck 2002) and evolutionary (Samani and Bell 2016; Bell 2017) processes are more likely to underpin EM. Ecological adaptation emphasizes the replacement of stress sensitive species with tolerant ones (a phenomenon described, amongst others, in the concept of pollution-induced community tolerance [PICT]; Blanck 2002). Evolutionary adaptation involves the selection of strains or organisms carrying genetic variants or modifications that confer resistance (Bell 2017). If these adaptations are partly or fully maintained during periods of non-stress, EM is established and the community can cope efficiently when the recurring stressor reappears (Padisak 1992; Scheffer and Carpenter 2003; Johnstone and others 2016). EM can contribute to enhance the stability of the ecosystem by promoting resistance and recovery (Donohue and others 2016; Hillebrand and others 2018). Resistance can be expressed by the ability to withstand stress, whereas recovery addresses the ability to regain normal functions and structures after being impacted (Hillebrand and others 2018). Resistance and recovery can be measured in terms of functional (for example, biomass production and resource use) and structural (community composition) characteristics (Hillebrand and others 2018).

Evidence of the causal relationship between earlier encounters to a stressor and present-day tolerance stems mostly from observational studies or theoretical models (Peterson 2002; Ogle and others 2015; Hughes and others 2019), while experimental approaches targeting natural communities are rare (Feckler and others 2018). An inherent limitation of observational approaches is that they typically focus on communities that are incidentally available at a given time point (snapshot), which might be blurred by other drivers (Cochran and Chambers 1965). Under such circumstances, the acquisition of adaptation may not be fully expressed or detectable during stress-free periods, despite still being present in an inactive form, that is, as dormant stage (Orsini and others 2013). Organisms that have the ability to produce long lasting resting stages represent a useful experimental model since these can act like "seed banks" containing previous species assemblages that span over an extended period of time (Orsini and others 2013). In phytoplankton, the formation of resting spores or cysts is a common strategy (Orsini and others 2013) and can be considered as natural biological archives that offer a good opportunity to study whether or how EM helps to recruit species that gained tolerance through past adaptations (Ellegaard and others 2018). Hence, phytoplankton germination experiments offer a good model to study EM (Padisak 1992). Moreover, some anthropogenic stressors, such as pesticides, are relatively well monitored and offer the prospect of investigating how communities that have been repeatedly exposed to the same stressor can develop tolerance (Blanck 2002). The contamination of freshwaters by pesticides from agricultural fields is one of the few stressors that have been monitored (Fölster and others 2014) over time scales (decades) relevant for ecological and evolutionary adaptation (Thompson 1998).

Pesticide (including insecticides, fungicides and herbicides) runoff from agricultural fields can adversely affect diversity (Tilman and others 2002), functioning and ecosystem services in freshwaters (Vörösmarty and others 2005, 2010; Weatherhead and Howden 2009). Pesticides can decrease the fitness of non-target aquatic organisms (Beketov and Liess 2008) by altering their enzyme activity and metabolism (Sturm and others 2007). They can also alter community structures (Rohr and Crumrine 2005) by increasing mortality of sensitive species (Schroer and others 2004). Herbicides specifically target groups of organisms that carry 
out photosynthesis such as phytoplankton (Brock and others 2000). Nevertheless, the long-term effects of herbicides exposure on algae still remain unclear (Schäfer and others 2011). Empirical evidence showed that certain herbicides (for example, Atrazine) can shift the distribution of sensitive species toward more tolerant species and thereby increase community tolerance (Bérard and Benninghoff 2001; Seguin and others 2002). However, the net cost of acquiring tolerance may involve a trade-off, for instance, with production. The most tolerant species may not be the most productive ones (Moe and others 2013; Rizzuto and others 2020). Such trade-offs are generally overlooked (Medina and others 2007).

Here, we used a two-phase experiment to evaluate the significance of EM in influencing the responses of natural phytoplankton from a lake that has been historically exposed to various herbicides that leached from the surrounding agricultural catchment. During the first phase of the experiment, phytoplankton assemblages were germinated (from sediments) and simultaneously conditioned to an herbicide (presence vs. absence of Isoproturon: $12 \mu \mathrm{g} / \mathrm{L}$ ), for 17 days. In the second phase of the experiment, communities that were obtained from the previous germination stage were exposed to a broader concentration gradient $(0 \mu \mathrm{g} / \mathrm{L}, 7 \mu \mathrm{g} / \mathrm{L}$, $12 \mu \mathrm{g} / \mathrm{L}, 61 \mu \mathrm{g} / \mathrm{L}$, and $92 \mu \mathrm{g} / \mathrm{L}$ ) of the same herbicide for 7 days. During the second phase of the experiment, functional endpoints related to production (total biomass and photosynthetic efficiency), and structural characterization of the phytoplankton assemblages (community composition) were monitored. We hypothesized $(\mathrm{Hl})$ that the presence of the herbicide (hereafter named conditioning) during germination of phytoplankton originating from the historically contaminated lake yields communities that are more structurally resistant and able to maintain a higher production under stress. The underlying assumption is that conditioning facilitates the recruitment of tolerant species (Kraft and others 2015), which were selectively favored by previous stress episodes. The selection process of tolerant species is captured by the PICT concept (Blanck 2002), whereas EM (Padisak 1992) adds a temporal dimension to the process and emphasizes the persistence of tolerant species over time. During non-stress periods, tolerant species might lose their advantages to more competitive non-tolerant species (Tilman 1982), but can still be present in seed banks and brought back during unfavorable conditions. To contrast with $\mathrm{Hl}$, the same conditioning and exposure procedures were applied to phytoplankton assem- blages that were germinated from lake sediments of a near-pristine, forested catchment, that had no historical exposure to the herbicide and therefore potentially lacked tolerant species and were potentially more vulnerable. In this case, we hypothesized $(\mathrm{H} 2)$ that conditioning is ineffective in yielding a more productive and structurally resistant community, due of the lack of EM and this can increase their sensitivity to the second herbicide exposure.

\section{Materials And Methods}

\section{Sediment Collection}

During August 2017, sediment was collected with a corer from two Swedish lakes that mainly differed in their catchments. The lakes have similar ambient climate, physical and chemical characteristics (trophic status, water depth and submerged aquatic macrophytes consisting mostly of Myriophyllum genus [watermilfoil]; Text S1, Figure S1). Finnsjön $\left(60^{\circ} 21^{\prime} 45.1^{\prime \prime} \mathrm{N}, 17^{\circ} 52^{\prime} 56.1^{\prime \prime} \mathrm{E}\right.$, ) is a near-pristine lake with a forest dominated catchment, and Tåkern $\left(58^{\circ} 21^{\prime} 07.0^{\prime \prime} \mathrm{N}, 14^{\circ} 49^{\prime} 42.7^{\prime \prime} \mathrm{E}\right)$ is a historically contaminated lake that drains from an area associated with intensive large-scale agricultural use (Text S2, Table S1). At least 15 different cores were collected from each lake. The upper oxic layer (ca. $5 \mathrm{~cm}$ ) from the sediment cores was carefully sectioned and temporarily stored in a cooler. Once in the laboratory, sediment samples from the same catchment were mixed to obtain an aggregated seed bank, then sieved (mesh size of $5 \mathrm{~mm}$ ) to remove large materials (stone, roots and debris) and stored in the dark at $4{ }^{\circ} \mathrm{C}$ until the start of the experiment.

\section{Model Stressor and Pilot Study}

The phenylurea herbicide Isoproturon was selected as a model stressor as it was commonly used and previously analyzed in the catchment of the historically impacted lake (Table S1). Isoproturon was widely used, for its inhibitory properties that disrupt the electron transport in photosystem II by binding to the protein Dl in the thylakoid membrane (Arnaud and others 1994), until its ban from use in the European Union in 2016. The concentrations of Isoproturon applied during the experiment were determined using an eco-toxicological test for growth inhibition (OECD guideline, Test No. 201) using laboratory-cultured algae (Pseudokirchneriella subcapitata, recently revised and renamed to Raphidocelis subcapitata (Suzuki and others 2018)) and phytoplankton community 
assemblages from the two selected lakes. Based on the results of the growth inhibition test (Text S2, Figure S2), four concentration levels were selected: 7, 12, 62 and $92 \mu \mathrm{g} / \mathrm{L}$ causing approximately 5, 10, 70 and $90 \%$ growth inhibition, respectively. During the first phase of the experiment, a single Isoproturon concentration $(12 \mu \mathrm{g} / \mathrm{L})$ was used for conditioning, while four increasing levels (Ll: 7, L2: 12, L3: 61 and L4: $92 \mu \mathrm{g} / \mathrm{L}$ ) of the same herbicide were used during the second phase of the experiment. The stability of Isoproturon was assessed during the experiment using liquid chromatography mass spectrometry (Text S3). The measured Isoproturon concentrations varied moderately between the replicates of the different tested concentrations (Table 1). The difference between the nominal and measured concentrations on average varied by $26 \%$ (Table 1 ).

\section{Experimental Details}

\section{Phase I: Germination and conditioning phase}

Phytoplankton communities were germinated from sediments in bioreactors (Figure 1). Bioreactors were divided into two equal sets. In one set, germination and conditioning to the presence $(+)$ of sub-lethal concentrations of Isoproturon $(12 \mu \mathrm{g} / \mathrm{L})$ occurred, whereas in the other set, Isoproturon was absent (-). Each unit (bioreactor) was replicated 5 times, resulting in a total of 20 germination microcosms. Well-homogenized subsamples of $3 \mathrm{~mL}$ sediment were transferred into $250 \mathrm{~mL}$ glass jars (total 20$)$. The glass jars $(250 \mathrm{~mL})$ containing the sediment were covered with steel woven nets (mesh size $60 \mu \mathrm{m}$ ) and were carefully placed into larger glass flasks (2.2L, Ikea, Sweden) before slowly adding $1.4 \mathrm{~L}$ of $\mathrm{Z8}$ medium (phosphate concentration of ca. $60 \mu \mathrm{g} / \mathrm{L})$ to the bioreactors. The steel net was used as a barrier for zooplankton grazers to prevent them from reaching the outer flask, if they emerged from resting stages. Once the bioreactors were filled with culture media, they were sealed with acrylic clip-lock caps fitted with two air inlets (glass tubes) and an air outlet to facilitate resuspension of algae by gently bubbling filtered $(0.2 \mu \mathrm{m}$, Whatman, UK) air in the flasks for $3 \mathrm{~min}$ at regular intervals of $15 \mathrm{~min}$. Isoproturon (Sigma-Aldrich, US) spiking solutions were prepared using dimethyl sulfoxide (DMSO) as a carrier solvent. Conditioning to Isoproturon during germination was achieved by pipetting $20 \mu \mathrm{L}$ of a DMSO solution containing $16.8 \mu \mathrm{g}$ Isoproturon to half of the bioreactors, to reach a final concentration of $12 \mu \mathrm{g} / \mathrm{L}$. Germination occurring in the absence of the Isoproturon (non-conditioned) was achieved by adding an equivalent volume of solvent only (DMSO) to the other half of the bioreactors, so as to rule out possible solvent-related effects. The bioreactors were kept overnight at $4{ }^{\circ} \mathrm{C}$. The following day the temperature was programmed to increase at an approximate rate of $0.5^{\circ} \mathrm{C} /$ hour to reach $13{ }^{\circ} \mathrm{C}$. Once the ambient temperature was reached, a diel light cycle was applied (light/dark: 16/8 h, $30 \mu \mathrm{mol}$ photons $\mathrm{m}^{-}$ ${ }^{2} \mathrm{~s}^{-1}$ light irradiance). The germination phase lasted for 17 days, and at the end, the replicates were bulked according to the four experimental units (Figure 1). Bulking of replicates according to the four different germination scenarios was deemed necessary as it gives the opportunity to standardize the starting conditions for phase II.

\section{Phase II: Isoproturon exposure}

In the second part of the experiment, subsamples from the bulk of each individual treatment were inoculated in Erlenmeyer flasks and exposed to an increasing gradient of Isoproturon levels (L1-L4) and a control $(0 \mu \mathrm{g} / \mathrm{L})$, each in triplicate (total of 60 experimental units; Figure 1). The inoculum was standardized using chlorophyll-a concentrations measured as in vivo fluorescence. The inocula were diluted with freshly prepared Z8 medium to reach a

Table 1. Comparison of the Nominal and Measured Concentrations, Expressed as Time Weighted Mean, of Isoproturon During the Two Different Phases of the Experiment.

\begin{tabular}{llll}
\hline Phase & Lake & Nominal concentrations $(\mu \mathrm{g} / \mathrm{L})$ & Time-weighted mean concentrations $(\mu \mathrm{g} / \mathrm{L})$ \\
\hline I & 12 & 17.25 \\
& Near-pristine & 12 & 17.81 \\
II & 7 & 9.19 \\
& Historically contaminated & 7 & 11.22 \\
& Near-pristine & 61 & 46.94 \\
& Historically contaminated & 61 & 54.67 \\
& Near-pristine & & \\
\hline
\end{tabular}




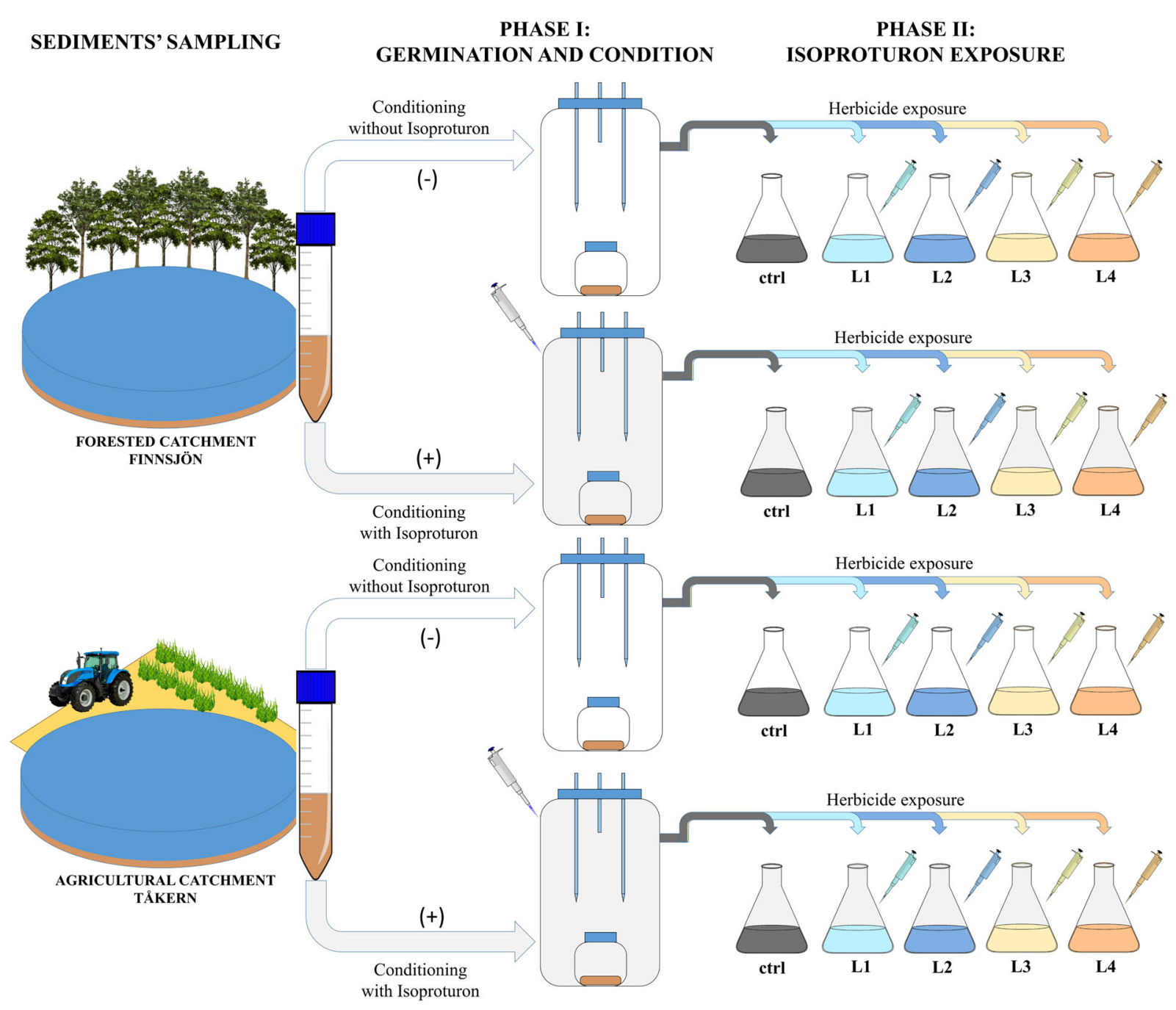

Figure 1. Conceptual figure illustrating the experiment design and the workflow divided into two phases: germination and exposure. During the first phase of the experiment, phytoplankton were germinated from seed banks while a subset (half) of the culture units was simultaneously conditioned with a sub-lethal concentration of Isoproturon ( $12 \mu \mathrm{g} / \mathrm{L}$ ). The communities obtained at the end of the germination phase were exposed to an increasing exposure concentration of Isoproturon (Ctrl: 0, L1: 7, L2: 12, L3: 61 and L4: $92 \mu \mathrm{g} / \mathrm{L}$ ).

final volume of $300 \mathrm{~mL}$ using the following dilution scheme: near-pristine $(-)$ 1:5, near-pristine $(+)$ $1: 7$, historically contaminated $(-) 1: 8$, historically contaminated $(+)$ 1:8. The standardized inocula were exposed to the Isoproturon gradient (L1-L4). The exposure phase lasted for 7 days.

\section{Phytoplankton Responses: Growth Rate, Total Biomass, Species Composition and Photosynthetic Efficiency}

The growth of phytoplankton was monitored daily during both phases using in vivo fluorescence, which was measured using a spectrophotometer (BioTek Synergy MX; Winosky, VT, USA). Triplicates from each sample $(300 \mu \mathrm{L}$ in each well) were loaded on 96 well clear flat-bottomed microplates (Corning, USA). Fluorescence was analyzed using the integrated software Gen 5 (BioTek, US) with excitation and emission wavelengths of $440 \mathrm{~nm}$ and $685 \mathrm{~nm}$, respectively. The growth rate $\mu \mathrm{g}\left(\mathrm{d}^{-1}\right)$ was calculated as the slope of a linear regression for log-transformed in vivo fluorescence data against time (Hagman and others 2019).

Samples were collected for species taxonomic identification at the end of both phases. They were analyzed from the bulked samples of phase I and from each replicate from phase II. The bulked samples of phase I were analyzed to downscale the effort used to identify species while providing adequate information to: (a) to evaluate differences 
across the two lakes and the effects of conditioning; and (b) help to characterize the starting community composition of the second phase of the experiment. Phytoplankton were identified using the Utermöhl technique (protocol: CEN-EN 15,204) and a light microscope, generally to the lowest taxonomic level (species). Total biomass $\left(\mathrm{mg} / \mathrm{m}^{3}\right)$ was calculated from geometric conversions based on a standard protocol (CEN-EN 16,695). Three diversity matrices were derived from the taxonomy data: species richness, Shannon diversity index and evenness.

The effects of Isoproturon on photosynthetic efficiency (maximum quantum yield $\left(\mathrm{F}_{\mathrm{v}} / \mathrm{F}_{\mathrm{m}}\right)$ of photosystem II) were quantified by using a modified procedure developed by Hanelt (1998), that involved measuring in vivo chlorophyll-a fluorescence by means of a portable pulse-amplitude modulated fluorometer (Water-PAM, Walz, Germany) and the software (WinControl, Walz) provided by the manufacturer. Prior to each measurement, the samples (aliquots of less than 10 $\mathrm{mL}$ ) were incubated in the dark for $3 \mathrm{~min}$. Thereafter, the minimum fluorescence $F_{o}$ was determined by applying weak red light pulses, followed by short pulses $(0.6 \mathrm{~s})$ of strong saturating light to record maximum florescence $F_{m}$. $F_{v}$ was calculated as the difference between the maximum and minimum fluorescence $\left(F_{v}=F_{m}-F_{o}\right)$, where the yield $\left(F_{v} / F_{m}\right)$ was indicative of the physiological status of the communities. The photosynthetic efficiency was measured at three different time points (day l, 3 and 7) during phase II of the experiment.

\section{Statistical Analysis}

All analyses were conducted using R (version 3.5.1) statistical software ( $\mathrm{R}$ Core Development Team 2015).

\section{Phytoplankton Growth Rate, Total Biomass, Species Diversity Matrices}

The growth rate, total biomass, species richness, Shannon diversity index and evenness of phytoplankton were analyzed using linear regression models. During phase I, the effects of two main factors: contamination history (2 groups: nearpristine lake vs. historically contaminated lake) and conditioning ( 2 groups: presence and absence of Isoproturon during germination) were tested. During phase II, the effects of the following three factors: contamination history (2 groups: nearpristine lake vs. historically contaminated lake), conditioning ( 2 groups: presence and absence of
Isoproturon during germination) and Isoproturon exposure (5 groups: control, L1-L4) were tested. Log transformation was used in some cases to fulfill the assumptions of normality. The interaction terms between the main factors were considered important for inference. When significant main effects were detected, pairwise comparisons based on estimated marginal means were used. Pairwise comparisons were complemented with effect sizes in some cases to assess the magnitude of treatment effects. Effect sizes based on Cohen's $d$ values were calculated by taking the mean difference between two groups that was then divided by the pooled standard deviation (Cohen 2013).

\section{Photosynthetic Efficiency}

Time series data for the photosynthetic efficiency measurements were analyzed using a repeated measurement analysis of variance (ANOVA). Huynh-Feldt correction was applied when the assumptions of sphericity were breached. The photosynthetic efficiency data recorded during the last sampling (day 7) point were analyzed using a linear model to assess if the effects of the Isoproturon exposures of phase II were significant.

\section{Phytoplankton Community Composition and Structural Resistance}

Multivariate analyses were used to evaluate the effects of the Isoproturon exposure (phase II) on the phytoplankton community composition and measure structural resistance. Non-metric multidimensional scaling (NMDS) based on Bray-Curtis similarity and square-root-transformed species matrix data obtained from the taxonomic analysis was used to assess the effect of Isoproturon exposure. NMDS analyses were complemented with permutational multivariate ANOVA using BrayCurtis similarity matrix, with 9,999 unrestricted permutations and applying Monte Carlo p-values corrections. Structural resistance was calculated using a similar method as previously described by Hillebrand and others (2018) that is based on geometric distance. Structural resistance was derived as Euclidean distance between the centroid coordinates of the control, relative to those of Isoproturon exposures levels (L1-L4). The centroid coordinates were extracted from the NMDS plots. The closer the distances between phytoplankton communities of the control and the respective Isoproturon exposure levels (L1-L4), the higher the resistance. 


\section{Results}

\section{Comparing Phytoplankton Communities} from the Two Lakes and Assessing the Influence of Conditioning (Phase I)

Germination started a few days earlier for the historically contaminated lake compared to the nearpristine lake (Figure S3); however, both lakes achieved similar growth rates (Figure 2A). The earlier initiation of phytoplankton growth from the historically contaminated lake subsequently led to a higher total biomass compared to assemblages that originated from the near-pristine lake $\left(F_{1,8}=230.08, \quad p<0.001, \quad\right.$ Figure 2B). Species richness (Figure S4A), Shannon diversity index (Figure 2C) and evenness (Figure S4B) of phytoplankton assemblages from the historically contaminated lake were substantially higher than the near-pristine lake (Table S2 and Figure S5). The species composition also differed between lakes (Figure 2D), and the proportion of Chrysophyceae was considerably higher in the near-pristine lake, whereas Chlorophyceae were the most abundant algae group in both lakes.

The effects of conditioning (that is, the presence of Isoproturon during germination) led to a de- crease in Shannon diversity index $\left(\mathrm{F}_{1,8}=32.90\right.$, $p<0.01)$ and evenness $\left(\mathrm{F}_{1,8}=15.35, p<0.05\right)$ in both lakes. In contrast, the effects of conditioning on the growth rate and species richness were negligible. Conditioning had a marginal effect on the total phytoplankton biomass $\left(\mathrm{F}_{1,8}=1.70\right.$, $p>0.05$ ), but appeared to significantly interact with the contamination history $\left(\mathrm{F}_{1,8}=9.68\right.$, $p<0.05$, Table S2). For instance, conditioning had a pronounced negative effect (Cohen' $d=3.89$ ) on the total phytoplankton biomass of the historically contaminated lake, whereas the opposite trend was observed for the near-pristine lake (Cohen' $d=2.1$ and Figure 2B). Besides total biomass, significant interaction between conditioning and contamination history was not observed for growth rate, species richness, Shannon diversity and evenness (Table S2). The species composition (Figure 2D) was marginally affected by conditioning.

\section{Effects of Isoproturon Exposure Gradient on Growth Rate, Total Biomass and Species Diversity (Phase II)}

Exposure to the Isoproturon gradient (L1-L4) during the second phase of the experiment signif-
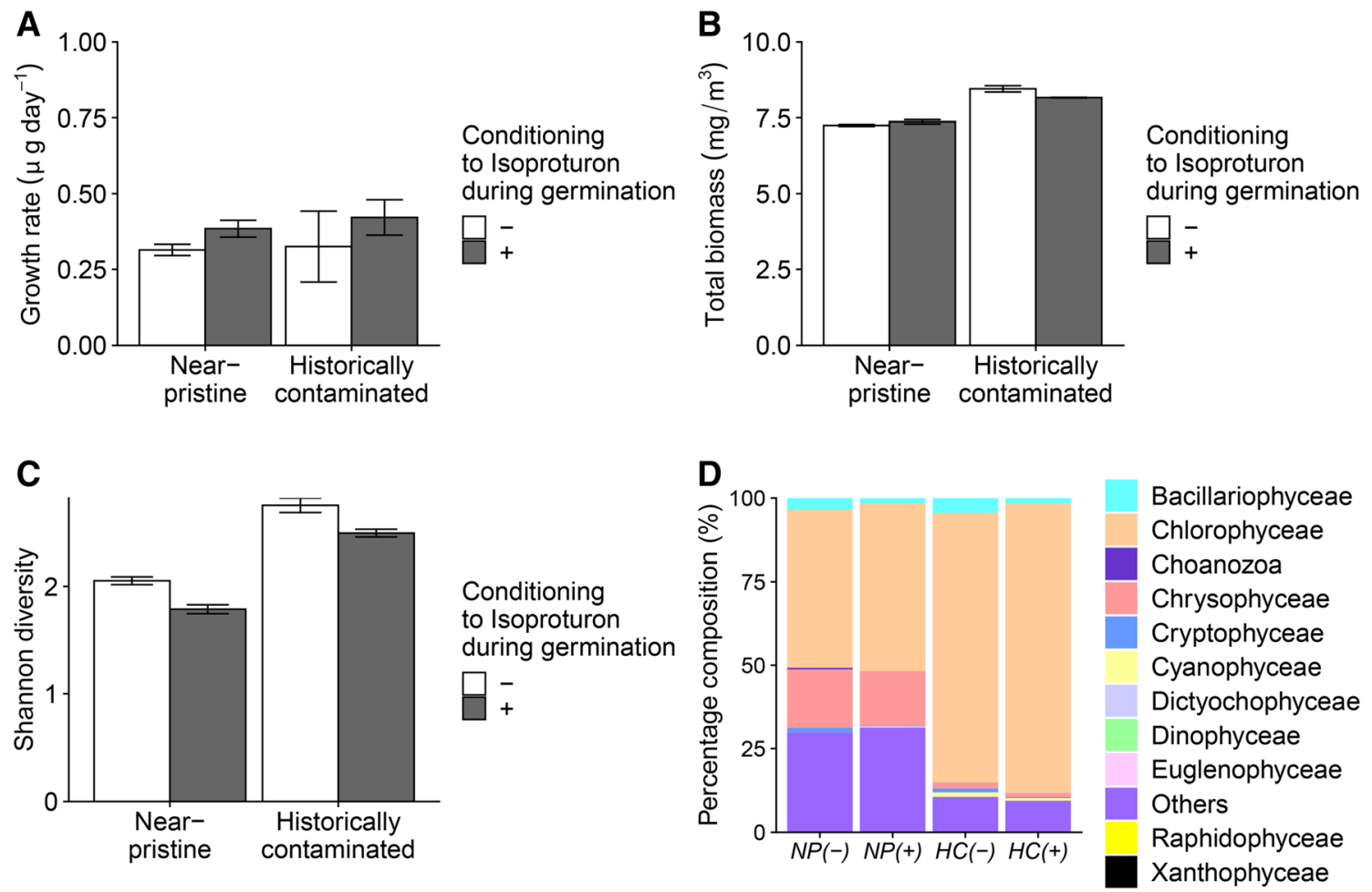

Figure 2. Effects of conditioning, during the first phase of the experiment, on growth rate (A), total biomass (B), Shannon diversity $(\mathbf{C})$ and the relative proportion of phytoplankton groups $(\mathbf{D})$ in the communities originated from the two lakes (NP: near-pristine, HC: historically contaminated). Error bars when present indicate standard error. 
Table 2. Summary of the Effects of the Contamination History, Conditioning, Isoproturon Exposure and the Interaction Term Between the Three Factors on Different Endpoints; Growth Rate, Total Biomass, Species Richness, Shannon Diversity and Evenness of Phytoplankton Recorded During the Second Phase of the Experiment.

\begin{tabular}{|c|c|c|c|c|c|}
\hline Variables & Effects & $d f$ & SS & $F$ & $p$ \\
\hline \multirow[t]{7}{*}{ Growth rate } & Isoproturon exposure & 4,60 & 2.09 & 89.25 & $<0.001$ \\
\hline & Conditioning & 1,60 & 0.01 & 2.27 & 0.14 \\
\hline & Contamination history (Con his.) & 1,60 & 0.09 & 14.92 & $<0.001$ \\
\hline & Isoproturon exposure: Conditioning & 4,60 & 0.01 & 0.61 & 0.66 \\
\hline & Isoproturon exposure: Con his & 4,60 & 0.01 & 0.34 & 0.85 \\
\hline & Conditioning: Con his & 1,60 & 0.03 & 4.88 & $<0.05$ \\
\hline & Isoproturon exposure: Conditioning: Con his & 4,60 & 0.02 & 0.76 & 0.55 \\
\hline \multirow[t]{7}{*}{ Total biomass } & Isoproturon exposure & 4,60 & 19.89 & 149.98 & $<0.001$ \\
\hline & Conditioning & 1,60 & 0.43 & 13.00 & $<0.001$ \\
\hline & Contamination history (Con his.) & 1,60 & 1.81 & $\mathbf{5 4 . 4 6}$ & $<0.001$ \\
\hline & Isoproturon exposure: Conditioning & 4,60 & 0.01 & 0.10 & 0.98 \\
\hline & Isoproturon exposure: Con his & 4,60 & 0.57 & 4.31 & $<0.01$ \\
\hline & Conditioning: Con his & 1,60 & 0.001 & 0.03 & 0.87 \\
\hline & Isoproturon exposure: Conditioning: Con his & 4,60 & 0.03 & 0.22 & 0.93 \\
\hline \multirow[t]{7}{*}{ Species richness } & Isoproturon exposure & 4,60 & 146.83 & 3.82 & $<0.05$ \\
\hline & Conditioning & 1,60 & 93.75 & 9.75 & $<0.01$ \\
\hline & Contamination history (Con his.) & 1,60 & 0.42 & 0.04 & 0.84 \\
\hline & Isoproturon exposure: Conditioning & 4,60 & 79.17 & 2.06 & 0.10 \\
\hline & Isoproturon exposure: Con his & 4,60 & 117.83 & 3.06 & $<0.05$ \\
\hline & Conditioning: Con his & 1,60 & 150.42 & 15.64 & $<0.001$ \\
\hline & Isoproturon exposure: Conditioning: Con his & 4,60 & 46.17 & 1.20 & 0.33 \\
\hline \multirow[t]{7}{*}{ Shannon diversity } & Isoproturon exposure & 4,60 & 0.10 & 1.92 & 0.13 \\
\hline & Conditioning & 1,60 & 0.23 & 17.10 & $<0.001$ \\
\hline & Contamination history (Con his.) & 1,60 & 0.69 & 51.80 & $<0.001$ \\
\hline & Isoproturon exposure: Conditioning & 4,60 & 0.13 & 2.36 & 0.07 \\
\hline & Isoproturon exposure: Con his & 4,60 & 1.44 & 26.77 & $<0.001$ \\
\hline & Conditioning: Con his & 1,60 & 0.20 & 14.78 & $<0.001$ \\
\hline & Isoproturon exposure: Conditioning: Con his & 4,60 & 0.07 & 1.36 & 0.26 \\
\hline \multirow{7}{*}{ Evenness } & Isoproturon exposure & 4,60 & 0.02 & 4.03 & $<0.01$ \\
\hline & Conditioning & 1,60 & 0.01 & 5.24 & $<0.05$ \\
\hline & Contamination history (Con his.) & 1,60 & 0.06 & 44.10 & $<0.001$ \\
\hline & Isoproturon exposure: Conditioning & 4,60 & 0.01 & 1.18 & 0.33 \\
\hline & Isoproturon exposure: Con his & 4,60 & 0.09 & 17.75 & $<0.001$ \\
\hline & Conditioning: Con his & 1,60 & 0.004 & 3.23 & 0.08 \\
\hline & Isoproturon exposure: Conditioning: Con his & 4,60 & 0.01 & 1.46 & 0.23 \\
\hline
\end{tabular}

icantly affected total phytoplankton biomass, growth rate, species richness, and evenness (Table 2, Figure 3). The interaction between Isoproturon exposure and contamination history was significant for total biomass, species richness, Shannon diversity and evenness, whereas interaction between conditioning and contamination history was significant for growth rate, species richness and Shannon diversity. Interactions involving all three factors (Isoproturon exposure, conditioning and contamination history) were not significant for any of measured variables (Table 2).

In addition, pairwise comparisons revealed some general patterns. For instance, exposure to the two highest Isoproturon levels (L3 and L4) led to a significant decrease in growth rate (Figure 4A) and total biomass (Figure 4B) of phytoplankton compared to the control and the low exposure levels (L1 and L2). The decrease in total biomass was more pronounced for the historically contaminated 
Table 3. Comparing Community Composition of the Near-pristine and the Historically Contaminated Lakes that Were Exposed to the Isoproturon Concentration Gradient.

\begin{tabular}{|c|c|c|c|c|c|}
\hline Contamination history & Conditioning & Isoproturon exposure & t-value & P-value & $\overline{\text { Euclidean distance }}$ \\
\hline \multirow[t]{8}{*}{ Near-pristine } & \multirow[t]{4}{*}{$(-)$} & $\mathrm{Ll}$ & 0.93 & 0.46 & 0.16 \\
\hline & & $\mathrm{L} 2$ & 1.37 & 0.19 & 0.29 \\
\hline & & L3 & 2.46 & 0.02 & 0.44 \\
\hline & & L4 & 3.21 & 0.01 & 0.38 \\
\hline & \multirow[t]{4}{*}{$(+)$} & $\mathrm{Ll}$ & 1.32 & 0.19 & 0.15 \\
\hline & & $\mathrm{L} 2$ & 1.61 & 0.09 & 0.26 \\
\hline & & L3 & 3.51 & 0.004 & 0.53 \\
\hline & & L4 & 4.43 & 0.002 & 0.53 \\
\hline \multirow[t]{8}{*}{ Historically Contaminated } & \multirow[t]{4}{*}{$(-)$} & $\mathrm{Ll}$ & 1.23 & 0.25 & 0.14 \\
\hline & & $\mathrm{L} 2$ & 1.66 & 0.08 & 0.08 \\
\hline & & L3 & 4.01 & 0.002 & 0.29 \\
\hline & & L4 & 4.23 & 0.002 & 0.33 \\
\hline & \multirow[t]{4}{*}{$(+)$} & $\mathrm{Ll}$ & 1.10 & 0.34 & 0.18 \\
\hline & & $\mathrm{L} 2$ & 0.88 & 0.48 & 0.23 \\
\hline & & L3 & 3.91 & 0.002 & 0.32 \\
\hline & & L4 & 3.98 & 0.004 & 0.20 \\
\hline
\end{tabular}

The Euclidean distance between the control and the different exposure levels (L1, L2, L3 and L4) centroids based on the NMDS plots, across the two lakes and the two different conditioning scenarios. Significant results are highlighted in bold.

lake (Cohen's d values; Table S3) when exposed to the highest levels of Isoproturon (L3-L4; Figures $3 \mathrm{~B}, 4 \mathrm{~B})$. The effects of conditioning on growth rate varied across the different Isoproturon exposure levels for the historically contaminated lake, whereas conditioning generally led to a slight increase in growth rate of phytoplankton for the near-pristine lake (Figures 3A, 4A). Nevertheless, growth rates of phytoplankton from the historically contaminated lake were consistently higher for the two highest exposure levels (L3 and L4) compared to the near-pristine lake (Figure 4A). The magnitude of change in the growth rate was also consistently higher (larger Cohen's d values between the control and the Isoproturon exposure levels LlL4) for the near-pristine lake compared to the historically contaminated lake (Table S3). The highest exposure levels (L3 and L4) reduced species richness only for communities of the near-pristine lake (Figure S6), that were conditioned to Isoproturon during germination. Shannon diversity and evenness of the historically contaminated lake increased with increasing herbicide levels, while the opposite was observed for the near-pristine lake (Figures 3C,D, 4C, D).

\section{Effects of Isoproturon Exposure Gradient on Photosynthetic Efficiency (Phase II)}

Exposure to the Isoproturon concentration gradient significantly decreased the photosynthetic yield of the phytoplankton of both lakes (near-pristine lake; $F_{4,20}=51.4, p<0.01$, historically contaminated lake; $F_{4,20}=15.2, p<0.01$ and Figure 5). Furthermore, significant time effects and the interaction between time and Isoproturon exposure were observed in both lakes (Table S4). The relative decrease in the photosynthetic yield was generally stronger at higher Isoproturon exposure levels (L3-L4). The changes in photosynthetic yield over time were remarkably distinct between the two lakes and the conditioning scenarios (Figure 5), in particular for the last time point (day 7). The effects of the herbicide were still significant in the near-pristine lake on the last sampling event (day 7; Table S5). Furthermore, the differences between the control and the two highest levels (L3 and L4) of the near-pristine phytoplankton assemblages were larger when they were conditioned to the herbicide (L3: $t=-9.6, p<0.01$, L4: $t=-11.8, p<0.01)$ compared to the nonconditioned scheme (L3: $t=-0.25, p=0.8$, L4: $t=-3.7, p<0.01)$. In the historically contaminated lake, the effects of the Isoproturon exposure on day 7 (Table S5) were still significant 

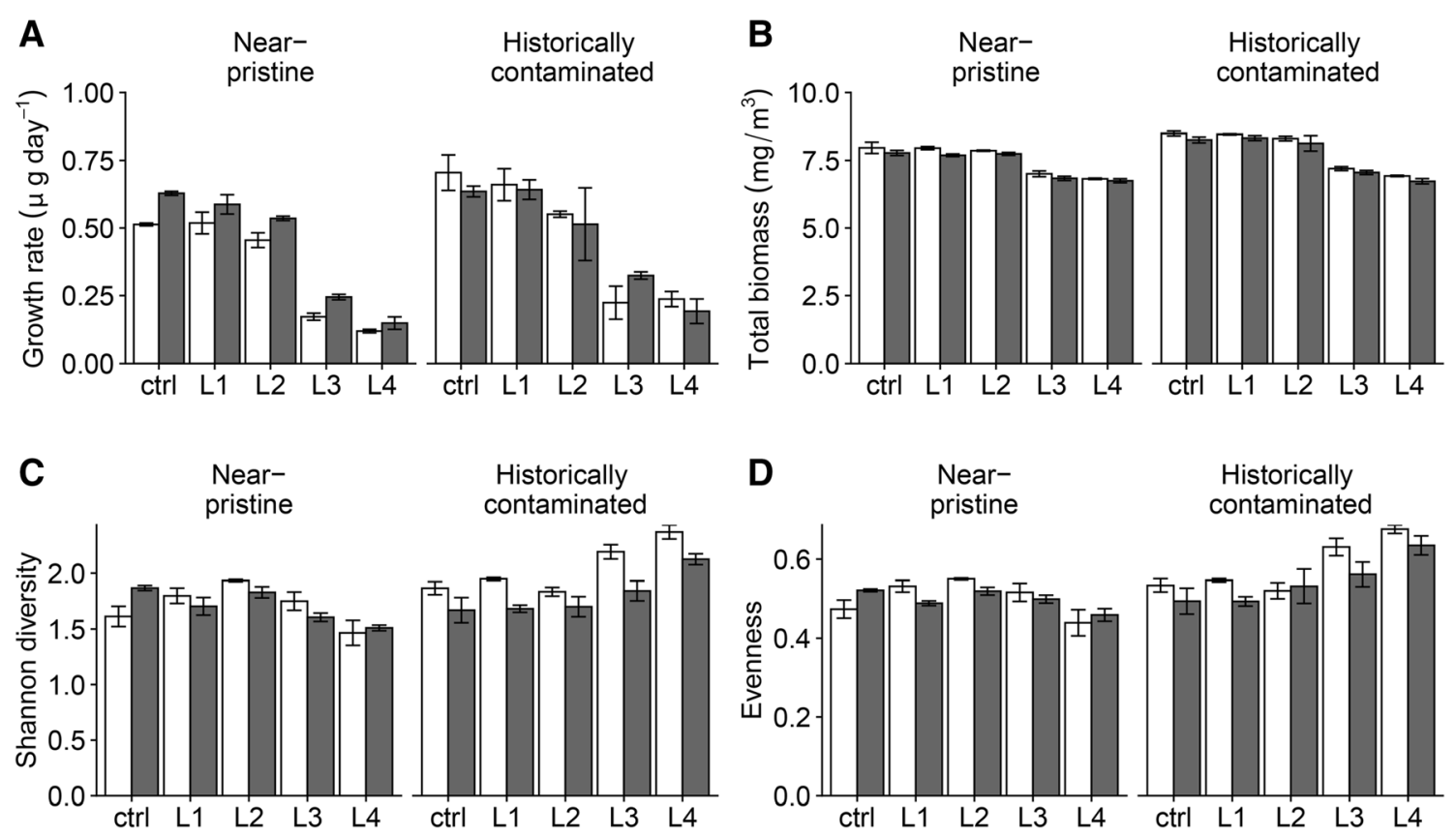

Conditioning to Isoproturon during germination Phase $\square-\square+$

Figure 3. Comparison of growth rate $(\mathbf{A})$, total biomass $(\mathbf{B})$, Shannon diversity index $(\mathbf{C})$ and evenness $(\mathbf{D})$ of phytoplankton originating from the near-pristine and the historically contaminated lake, along the Isoproturon exposure gradient (Ll-L4) used during the second phase of the experiment. Error bars indicate standard error.

$\left(F_{4,15}=7.91, p<0.01\right)$ when conditioning was omitted during germination.

\section{Effects of Isoproturon Exposure Gradient on Community Composition (Phase II)}

The composition of communities changed significantly (PERMANOVA: Table S6) in response to Isoproturon exposure. The relative proportions of most taxa decreased with increasing exposure levels (Figure 6A), apart from two groups (Chrysophyceae and unidentified group (others)) that increased in relative proportion at the two highest herbicide treatment levels.

Changes in community composition, depicted by the non-metric multidimensional scaling (NMDS) analyses (Figure 6B), were most pronounced at the highest exposure levels and reflected both the contamination history and conditioning during germination. Phytoplankton communities from the historically contaminated lake that underwent conditioning displayed higher structural resistance to the Isoproturon exposure. The distance between the control and the highest Isoproturon exposure level (L4) was shortened (Table 3, Figure 6B) when conditioning was applied during germination compared to the non-conditioned analogs. The opposite was observed for the communities origi- nating from the near-pristine lake system with regard to conditioning (Table 3, Figure 6B).

\section{Discussion}

This study provides a proof of concept of the relevance of EM in influencing ecosystem stability during the resurgence of a recurrent stressor. In particular, we focused here on conditioning as a trigger for retrieving adaptations nested in EM that may not be expressed in the community assemblages during periods of non-stress. We took advantage of lakes with different herbicide exposure histories to obtain communities with and without "memory" of Isoproturon stress to test our hypotheses. However, it is important to acknowledge that beyond historical exposure to herbicides, the lakes also differ in other respects (for example, differences in catchment characteristics, level of connectedness with other systems and so on). To rule out confounding effects posed by these factors, we focused on studying EM to a specific stressor by "retrieving" EM for Isoproturon through conditioning (that is, by applying the same stressor during germination). Conditioning was used as a means to facilitate the recruitment of tolerant strains/species that were already present in dor- 


\section{A}

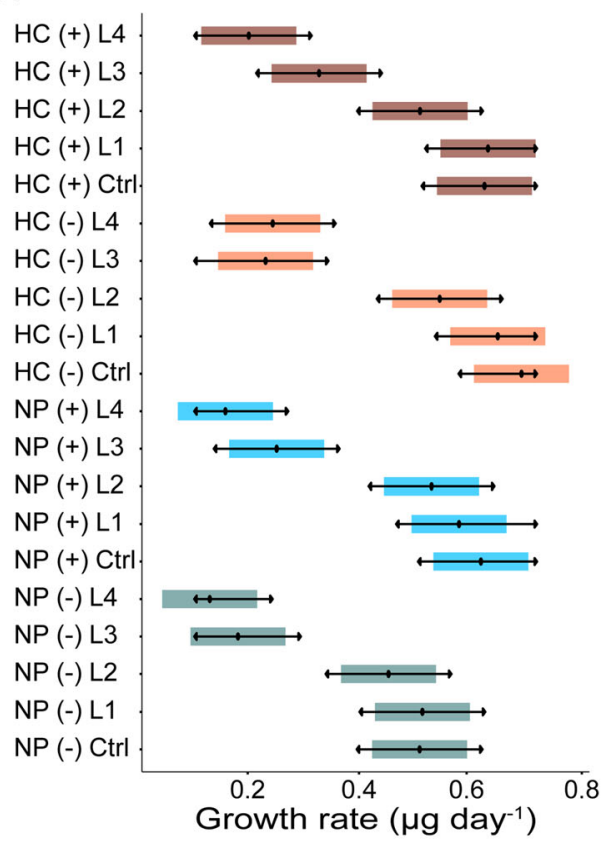

C

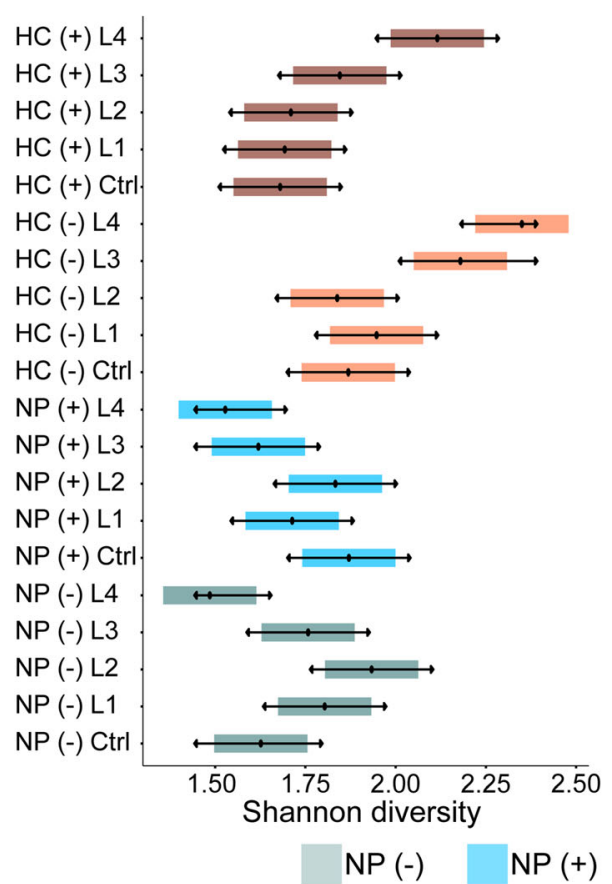

B

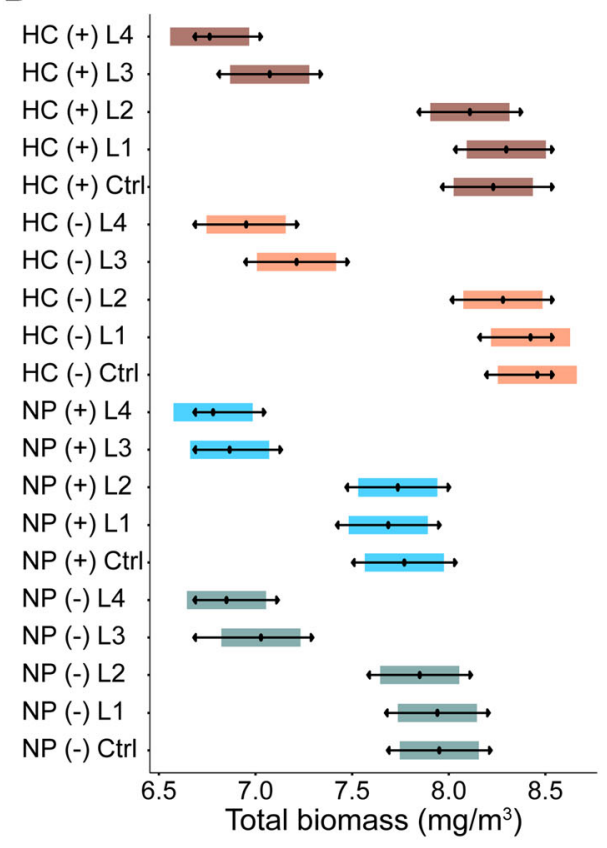

D

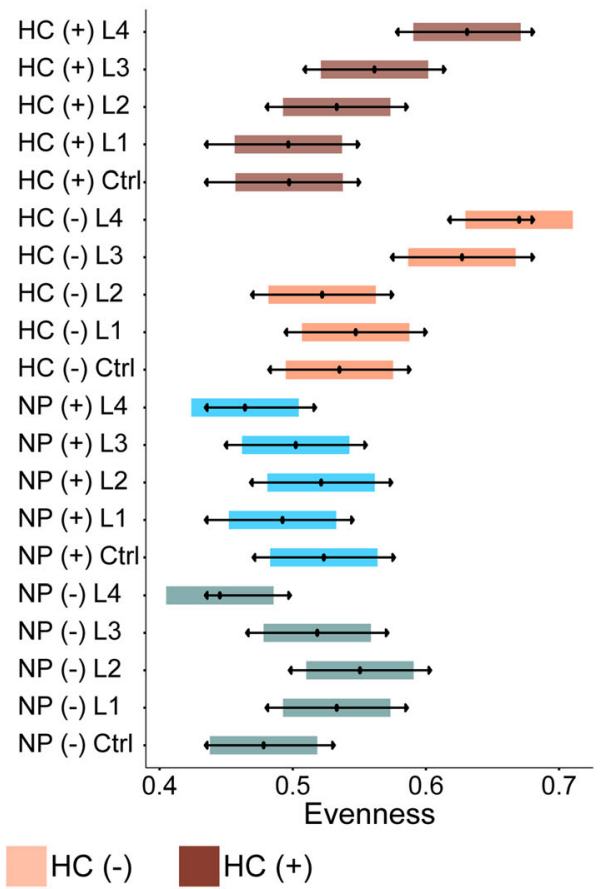

Figure 4. Pairwise comparison based on estimated marginal means for the growth rate (A), total biomass $(\mathbf{B})$, Shannon diversity index $(\mathbf{C})$ and evenness $(\mathbf{D})$ of phytoplankton observed during the second phase of the experiment. The central points in the figure indicate the mean response with $95 \%$ confidence interval for the combined main effects (contamination history, conditioning, Isoproturon exposure) for the near pristine (NP) lake and the historically contaminated (HC) lake that were conditioned with (+) and without $(-)$ Isoproturon during germination.

mant stages in the sediment of the historically contaminated lake. The experiment with phytoplankton communities from the near-pristine lake should therefore not be considered as a direct term of comparison but as a means to refute $\mathrm{Hl}$, and therefore test its robustness. Phase I of the experi- 


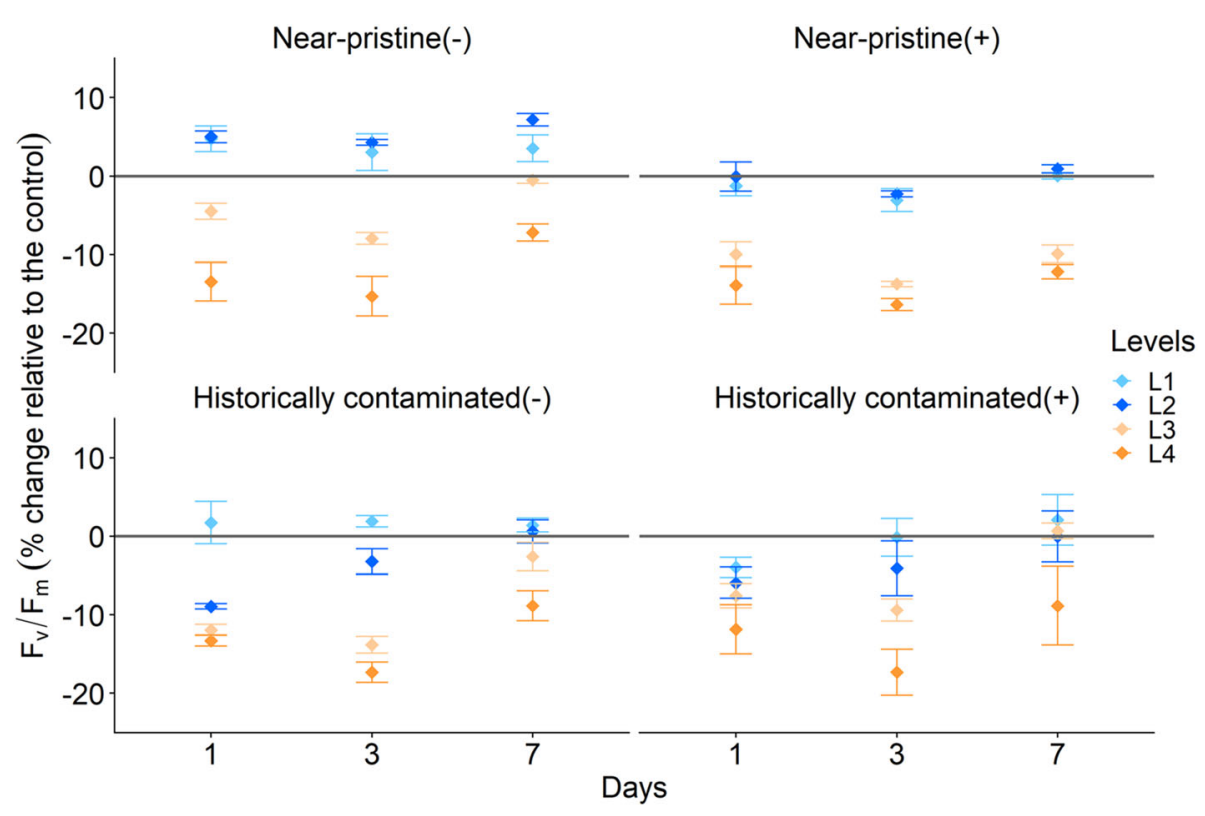

Figure 5. Photosynthetic efficiency (Fv/Fm): Percentage of change relative to control in the near-pristine and historically contaminated phytoplankton communities that were conditioned with $(+)$ and without (-) Isoproturon during germination. Error bars indicate standard error.

mental design was conceived to assemble natural communities harboring different genotypes from two lakes that differed in contamination histories. During phase II, EM is evaluated by assessing the ability of phytoplankton assemblages from the historically contaminated lake to maintain high production and stable composition under the Isoproturon gradient.

The results from phase II of the experiment support our expectations that conditioning of the community from the historically contaminated lake facilitates the recruitment of tolerant species that had acquired adaptation in the past. Phytoplankton assemblages from the historically contaminated lake, upon conditioning, were in fact able to restore photosynthetic efficiency (Figure 5) and proved to be structurally (Figure 6 and Table 3) more resistant when exposed to an increasing gradient of Isoproturon. At the same time, conditioning did not lead to the same effect in the near pristine lake (Figures 5, 6 and Table 3).

\section{Implications of EM for Production: Total Biomass and Photosynthetic Efficiency}

Total biomass and photosynthetic efficiency were monitored during the second phase of the experiment. The behavior of the two parameters differed markedly and was dependent on the lake contamination background and conditioning. Conditioning did not increase the total phytoplankton biomass (Figure 3B) irrespective of the lakes' contamination history. In contrast, photosynthetic efficiency was restored within a few days, despite being impacted in the earlier stage of the second phase of the experiment (Figure 5), while Isoproturon was still present (Table 1). However, such an improvement in restoring photosynthetic efficiency was only observed in phytoplankton assemblages that originated from the historically contaminated lake following conditioning during gemination (Figure 5). The contrasting responses between photosynthetic efficiency and biomass development can reflect differences in the temporal scales of these processes (Kriegman and others 2018). Physiological responses, such as photosynthetic efficiency, occur more rapidly and most likely reflect changes in the regulation of photosystem reaction centers (Antonacci and others 2018). This type of response is expected for organisms exposed to Isoproturon, as this herbicide is a photosystem II inhibitor (Antonacci and others 2018). Herbicideresistance has been shown to occur following a substitution mutation that altered structure of the targeted intracellular site, for example, the Dl protein of Photosystem II (Antonacci and others 2018). The improvement in photosynthetic efficiency might be linked to an increase in the prevalence of species/strains that express a mutation of the Dl protein of the photosystem reaction center to counteract the inhibitory effects of Isoproturon (Antonacci and others 2018). In contrast 
A
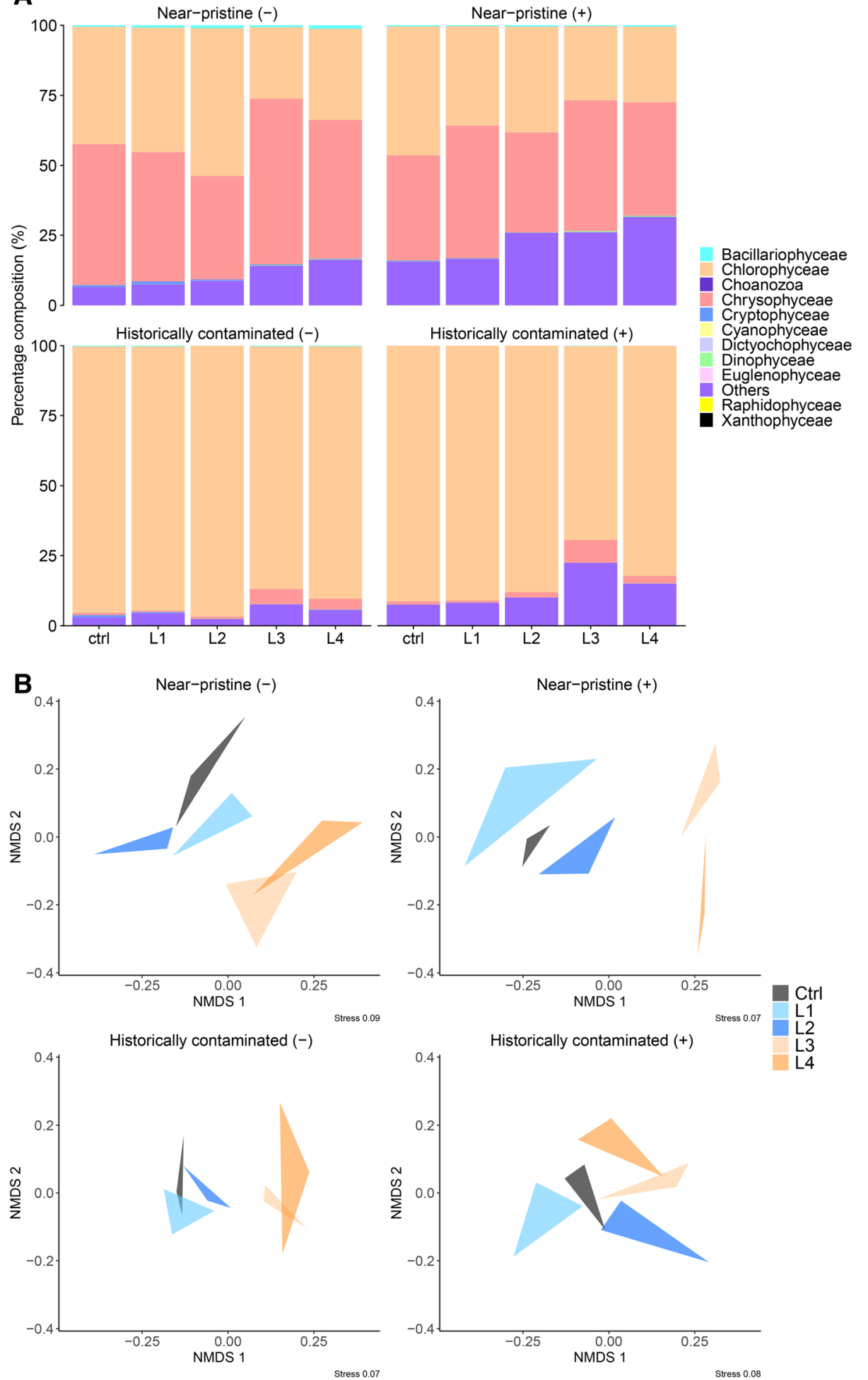

Figure 6. Changes in community structure observed during the exposure phase. (A) Percentage composition (relative abundances) of the major phytoplankton groups identified in the two lake (near-pristine and historically contaminated) conditioned without $(-)$ and with (+) Isoproturon (B) non-metric multidimensional scaling plot (NMDS) from the four experimental units. The corners of the polygons represent the replicates. 
to photosynthetic efficiency, biomass development may reflect changes in energy and resource allocation within organisms that might occur at a slower pace (van Straalen and Hoffmann 2000). This time lag might explain the lack of higher total biomass mediated by EM (Tilmon 2008; Hertz and others 2013), perhaps also due to the relatively short duration (7 days) of the second phase the experiment.

\section{Implications of Ecological Memory for Structural Resistance}

Following conditioning, the community composition of phytoplankton from the historically contaminated lake displayed a higher structural resistance (Figure 6 and Table 3), compared to the non-conditioned ones. Here, we observed that the distance between the centroids of the control and Isoproturon exposure levels (especially L4) for the phytoplankton communities decreased when conditioning was applied to phytoplankton from the historically contaminated lake. These results support our initial hypothesis (H1) concerning the structural stability aspects and suggest that phytoplankton communities that have been previously exposed to a stressor can boost their capacity to cope with subsequent encounters to the same stressor (Johnstone and others 2016). Such an increase in structural resistance was not observed in either the conditioned or the non-conditioned communities from the near-pristine lake, thus supporting H2. Regardless of conditioning, phytoplankton from the near-pristine lake showed weaker structural resistance (Figure 6B, Table 3). In this case, the distance between the centroids of controls and the two highest treatment levels (L3 and L4; Figure 6B, Table 3) actually increased as a consequence of conditioning, suggesting an increase in community sensitivity.

Moreover, the benefits of ecological memory in promoting structural resistance might involve a fundamental trade-off with the ability to maintain high biomass production (Vinebrooke and others 2004). Our results only provide some evidence of such a trade-off under a short-term designed experiment. For instance, the communities from the historically contaminated lake had a higher growth rate than the near-pristine lake (Figure 3) for the two highest treatment levels, but this did not result in larger biomass; this may relate to the occurrence of a trade-off. Similar trade-offs (that is the negative relationship between acquiring tolerance and building biomass) were observed by others (Coley and others 1985; Strauss and others
2002; Boivin and others 2003; Vila-Aiub and others 2009) as the most tolerant species might not necessarily be the most productive ones (Moe and others 2013; Rizzuto and others 2020). Further research is needed to fully elucidate trade-offs in the context of EM and over longer time scales.

Long-term herbicide exposure can favor the selection of tolerant strains (Schäfer and others 2011) or species that could be stored and eventually retrieved from seed banks. The selection of tolerant species can occur through ecological adaptation. Ecological adaptation acknowledges the replacement of sensitive species with tolerant ones (that is, pollution-induced community tolerance [PICT]; Blanck 2002), thereby helping to maintain key processes and structures. Previous empirical evidence showed that certain herbicides can shift the distribution of sensitive species toward more tolerant species and thereby increase the community tolerance (Bérard and Benninghoff 2001; Seguin and others 2002). In the present study, the hypothesis of an increase in the prevalence of tolerant species after conditioning was supported by the observed increase in Shannon diversity and evenness along the herbicide exposure gradient, which only occurred in phytoplankton assemblages of the historically contaminated lake (Figures 3C, $\mathrm{D}, 4 \mathrm{C}, \mathrm{D})$. Changes in evenness have previously been shown to be a more robust indicator of ecological change than species richness (Hillebrand and others 2008), which is in line with our findings.

Altogether, these results indicate that: (a) acquired structural resistance by the community is a consequence of retrieving EM through conditioning; and (b) EM is an attribute only of the systems that had historically been exposed to Isoproturon or other herbicides with a similar mode of toxic action. Since EM was retained in dormant stages, the role of conditioning was crucial in facilitating the recruitment of tolerant species, which were selectively favored by previous stress episodes.

These results complement previous findings and provide new insights on the concept of EM. Hughes and others (2019) described beneficial effects of EM in coral reefs exposed to two successive heat wave events causing bleaching. The authors showed that the mortality of coral reefs decreased after the second heat episode (in 2017) compared to the first one (in 2016), where the first event increased the proportion of resistant species (Hughes and others 2019). In another study, Feckler and others (2018) showed that the performance of microbial communities in decomposing leaf-litter from an agricultural stream was enhanced under exposure to 
pesticides compared to a community from a nearpristine stream. In addition to earlier assessments, our results strengthen the perception that previous encounters with a stressor matter (Samani and Bell 2016) and can increase structural resistance, even when these adaptations are not present or prevalent in the standing crop community.

\section{ConClusion}

We used an experimental approach to test an ecological concept (EM) that has previously remained elusive to empirical testing. We showed that adaptations from past experience that are present in dormant phytoplankton stages in lake sediments can be readily expressed when stressors reappear. Our results show the beneficial effects of EM in restoring certain processes (for example, photosynthetic efficiency) and increasing structural resistance of the phytoplankton communities. However, they also indicate a trade-off between resistance and other processes related to biomass production. The lack of EM to herbicide in the phytoplankton from the near-pristine lake system did not measurably yield stress tolerant species and structurally resistant communities. In addition, other processes related to spatial distribution and dispersal of species (for example, dispersal of metacommunities: Leibold and others 2004) can also influence ecosystems and contribute to stability toward the stressors. Better knowledge of these temporal (EM) and spatial (dispersal of metacommunities) processes are essential to gain a deeper understanding of the abilities of ecosystems to cope with recurrent stress.

\section{ACKNOWLEDGEMENTS}

The authors wish to thank Per Færøvig from the Section of Aquatic Biology and Ecotoxicology, University of Oslo for helping with the experimental setup. The authors thank: Vladyslava Hostyeva and Petra Mutinova from Culture Collection of Algae (NIVA-CCA) of the Norwegian Institute for Water Research (NIVA) for preparing the nutrient medium used during the experiment; and the personnel from the visitor centre of Tåkern Naturum for lending us their boat during sampling. This study was co-funded by the Research Council of Norway (contract 244460) for the PEACE (Pollution and Ecosystem Adaptation to Changes in the Environment) project and an internal grant from NIVA under the Institute Strategic Priorities (SIS) on ecosystem remediation (TRADE-OFF). SR was supported by the Lancaster University Faculty of
Science and Technology and a Lancaster Environment Centre PhD scholarship.

\section{OPEN ACCESS}

This article is licensed under a Creative Commons Attribution 4.0 International License, which permits use, sharing, adaptation, distribution and reproduction in any medium or format, as long as you give appropriate credit to the original author(s) and the source, provide a link to the Creative Commons licence, and indicate if changes were made. The images or other third party material in this article are included in the article's Creative Commons licence, unless indicated otherwise in a credit line to the material. If material is not included in the article's Creative Commons licence and your intended use is not permitted by statutory regulation or exceeds the permitted use, you will need to obtain permission directly from the copyright holder. To view a copy of this licence, visit $h$ ttp://creativecommons.org/licenses/by/4.0/.

\section{DATA AVAILABILITY}

Data are available at: https://doi.org/10.6084/m9.f igshare.13554689.v1.

\section{REFERENCES}

Antonacci A, Lambreva MD, Margonelli A, Sobolev AP, Pastorelli S, Bertalan I, Johanningmeier U, Sobolev V, Samish I, Edelman M, Havurinne V, Tyystjärvi E, Giardi MT, Mattoo AK, Rea G. 2018. Photosystem-II Dl protein mutants of Chlamydomonas reinhardtii in relation to metabolic rewiring and remodelling of $\mathrm{H}$-bond network at QB site. Sci Rep 8: 14745 .

Arnaud L, Taillandier G, Kaouadji M, Ravanel P, Tissut M. 1994. Photosynthesis Inhibition by Phenylureas: A QSAR Approach. Ecotoxicol Environ Saf 28:121-133.

Beketov MA, Liess M. 2008. Potential of 11 pesticides to initiate downstream drift of stream macroinvertebrates. Arch Environ Contam Toxicol 55:247-253.

Bell G. 2017. Evolutionary rescue. Annu Rev Ecol Evol Syst 48:605-627.

Bérard A, Benninghoff C. 2001. Pollution-induced community tolerance (PICT) and seasonal variations in the sensitivity of phytoplankton to atrazine in nanocosms. Chemosphere 45:427-437.

Blanck H. 2002. A critical review of procedures and approaches used for assessing pollution-induced community tolerance (PICT) in biotic communities. Hum Ecol Risk Assess Int J 8:1003-1034.

Boivin T, Bouvier JC, Chadœuf J, Beslay D, Sauphanor B. 2003. Constraints on adaptive mutations in the codling moth Cydia pomonella (L.): measuring fitness trade-offs and natural selection. Heredity 90:107-113.

Brock TCM, Lahr J, Van den Brink PJ. 2000. Ecological risks of pesticides in freshwater ecosystems; Part 1: herbicides. Alterra 
Cochran WG, Chambers SP. 1965. The planning of observational studies of human populations. J R Stat Soc Ser Gen 128:234266.

Cohen J. 2013. Statistical power analysis for the behavioral sciences, Revised. New York: Academic Press.

Coley PD, Bryant JP, Chapin FS. 1985. Resource availability and plant antiherbivore defense. Science 230:895.

Collins S, Gardner A. 2009. Integrating physiological, ecological and evolutionary change: a Price equation approach. Ecol Lett 12:744-757.

Donohue I, Hillebrand H, Montoya JM, Petchey OL, Pimm SL, Fowler MS, Healy K, Jackson AL, Lurgi M, McClean D, $\mathrm{O}^{\prime}$ Connor NE, O'Gorman EJ, Yang Q. 2016. Navigating the complexity of ecological stability. Ecol Lett 19:1172-1185.

Ellegaard M, Godhe A, Ribeiro S. 2018. Time capsules in natural sediment archives-tracking phytoplankton population genetic diversity and adaptation over multidecadal timescales in the face of environmental change. Evol Appl 11:11-16.

Feckler A, Goedkoop W, Konschak M, Bundschuh R, Kenngott KGJ, Schulz R, Zubrod JP, Bundschuh M. 2018. History matters: Heterotrophic microbial community structure and function adapt to multiple stressors. Glob Change Biol 24:e402-e415.

Fölster J, Johnson RK, Futter MN, Wilander A. 2014. The Swedish monitoring of surface waters: 50 years of adaptive monitoring. AMBIO 43:3-18.

Hagman CHC, Skjelbred B, Thrane J-E, Andersen T, de Wit HA. 2019. Growth responses of the nuisance algae Gonyostomum semen (Raphidophyceae) to DOC and associated alterations of light quality and quantity. Aquat Microb Ecol 82:241-251.

Hanelt D. 1998. Capability of dynamic photoinhibition in Arctic macroalgae is related to their depth distribution. Mar Biol 131:361-369.

Hertz PE, Arima Y, Harrison A, Huey RB, Losos JB, Glor RE. 2013. Asynchronous evolution of physiology and morphology in anolis lizards. Evolution 67:2101-2113.

Hillebrand H, Bennett DM, Cadotte MW. 2008. Consequences of dominance: a review of evenness effects on local and regional ecosystem processes. Ecology 89:1510-1520.

Hillebrand H, Langenheder S, Lebret K, Lindström E, Östman Ö, Striebel M. 2018. Decomposing multiple dimensions of stability in global change experiments. Ecol Lett 21:21-30.

Hughes TP, Kerry JT, Connolly SR, Baird AH, Eakin CM, Heron SF, Hoey AS, Hoogenboom MO, Jacobson M, Liu G, Pratchett MS, Skirving W, Torda G. 2019. Ecological memory modifies the cumulative impact of recurrent climate extremes. Nat Clim Change 9:40-43.

Johnstone JF, Allen CD, Franklin JF, Frelich LE, Harvey BJ, Higuera PE, Mack MC, Meentemeyer RK, Metz MR, Perry GL, Schoennagel T, Turner MG. 2016. Changing disturbance regimes, ecological memory, and forest resilience. Front Ecol Environ 14:369-378.

Kraft NJB, Adler PB, Godoy O, James EC, Fuller S, Levine JM. 2015. Community assembly, coexistence and the environmental filtering metaphor. Funct Ecol 29:592-599.

Kriegman S, Cheney N, Bongard J. 2018. How morphological development can guide evolution. Sci Rep 8:13934.

Leibold MA, Holyoak M, Mouquet N, Amarasekare P, Chase JM, Hoopes MF, Holt RD, Shurin JB, Law R, Tilman D, Loreau M, Gonzalez A. 2004. The metacommunity concept: a framework for multi-scale community ecology. Ecol Lett 7:601-613.
Medina MH, Correa JA, Barata C. 2007. Micro-evolution due to pollution: possible consequences for ecosystem responses to toxic stress. Chemosphere 67:2105-2114.

Moe SJ, De Schamphelaere K, Clements WH, Sorensen MT, Van den Brink PJ, Liess M. 2013. Combined and interactive effects of global climate change and toxicants on populations and communities. Environ Toxicol Chem Setac 32:49-61.

Ogle K, Barber JJ, Barron-Gafford GA, Bentley LP, Young JM Huxman TE, Loik ME, Tissue DT. 2015. Quantifying ecological memory in plant and ecosystem processes. Ecol Lett 18:221235

Orsini L, Schwenk K, De Meester L, Colbourne JK, Pfrender ME, Weider LJ. 2013. The evolutionary time machine: using dormant propagules to forecast how populations can adapt to changing environments. Trends Ecol Evol 28:274-282.

Padisak J. 1992. Seasonal succession of phytoplankton in a Large Shallow Lake (Balaton, Hungary) - a dynamic approach to ecological memory, its possible role and mechanisms. J Ecol $80: 217-230$

Peterson GD. 2002. Contagious disturbance, ecological memory, and the emergence of landscape pattern. Ecosystems 5:329338.

R Core Development Team. 2015. R: A Language and Environment for Statistical Computing.

Rizzuto S, Thrane J-E, Baho DL, Jones KC, Zhang H, Hessen DO, Nizzetto L, Leu E. 2020. Water browning controls adaptation and associated trade-offs in phytoplankton stressed by chemical pollution. Environ Sci Technol 54:5569-5579.

Rohr JR, Crumrine PW. 2005. Effects of an herbicide and an insecticide on pond community structure and processeS. Ecol Appl 15:1135-1147.

Samani P, Bell G. 2016. The ghosts of selection past reduces the probability of plastic rescue but increases the likelihood of evolutionary rescue to novel stressors in experimental populations of wild yeast. Ecol Lett 19:289-298.

Schäfer RB, van den Brink PJ, Liess M. 2011. Impacts of pesticides on freshwater ecosystems. Ecol Impacts Toxic Chem:111-37.

Scheffer M, Carpenter SR. 2003. Catastrophic regime shifts in ecosystems: linking theory to observation. Trends Ecol Evol $18: 648-656$

Schroer AFW, Belgers JDM, Brock CM, Matser AM, Maund SJ, Van den Brink PJ. 2004. Comparison of laboratory single species and field population-level effects of the pyrethroid insecticide $\lambda$-cyhalothrin on freshwater invertebrates. Arch Environ Contam Toxicol 46:324-335.

Seguin F, Le Bihan F, Leboulanger C, Bérard A. 2002. A risk assessment of pollution: induction of atrazine tolerance in phytoplankton communities in freshwater outdoor mesocosms, using chlorophyll fluorescence as an endpoint. Water Res 36:3227-3236.

Strauss SY, Rudgers JA, Lau JA, Irwin RE. 2002. Direct and ecological costs of resistance to herbivory. Trends Ecol Evol 17:278-285.

Sturm A, Radau TS, Hahn T, Schulz R. 2007. Inhibition of rainbow trout acetylcholinesterase by aqueous and suspended particle-associated organophosphorous insecticides. Chemosphere 68:605-612.

Suzuki S, Yamaguchi H, Nakajima N, Kawachi M. 2018. Raphidocelis subcapitata (=Pseudokirchneriella subcapitata) provides an insight into genome evolution and environmental adaptations in the Sphaeropleales. Sci Rep 8:8058. 
Thompson JN. 1998. Rapid evolution as an ecological process. Trends Ecol Evol 13:329-332.

Tilman D. 1982. Resource competition and community structure. Princeton University Press.

Tilman D, Cassman KG, Matson PA, Naylor R, Polasky S. 2002. Agricultural sustainability and intensive production practices. Nature 418:671-677.

Tilmon KJ. 2008. Specialization, Speciation, and Radiation. 1st ed. University of California Press. https://doi.org/10.1525/j.c ttlpnq3k

Turner MG. 2010. Disturbance and landscape dynamics in a changing world. Ecology 91:2833-2849.

van Straalen NM, Hoffmann AA. 2000. Review of experimental evidence for physiological costs of tolerance to toxicants. In: Kammenga JE, Laskowski R, editors. Demography in Ecotoxicology. John Wiley and Sons. pp 147-61. https://research. vu.nl/en/publications/ccdfbf36-eelc-4050-a0ef-e6ed63169b9 1
Vila-Aiub MM, Neve P, Powles SB. 2009. Evidence for an ecological cost of enhanced herbicide metabolism in Lolium rigidum. J Ecol 97:772-780.

Vinebrooke RD, Cottingham KL, Norberg J, Scheffer M, Dodson SI, Maberly SC, Sommer U. 2004. Impacts of multiple stressors on biodiversity and ecosystem functioning: the role of species co-tolerance. Oikos 104:451-457.

Vörösmarty CJ, Léveque C, Revenga C, Bos R, Caudill C, Chilton J, Douglas EM, Meybeck M, Prager D, Balvanera P. 2005. Fresh water. Millenn Ecosyst Assess 1:165-207.

Vörösmarty CJ, McIntyre PB, Gessner MO, Dudgeon D, Prusevich A, Green P, Glidden S, Bunn SE, Sullivan CA, Liermann CR, Davies PM. 2010. Global threats to human water security and river biodiversity. Nature 467:555.

Weatherhead EK, Howden NJK. 2009. The relationship between land use and surface water resources in the UK. Land Use Futur 26:S243-S250. 